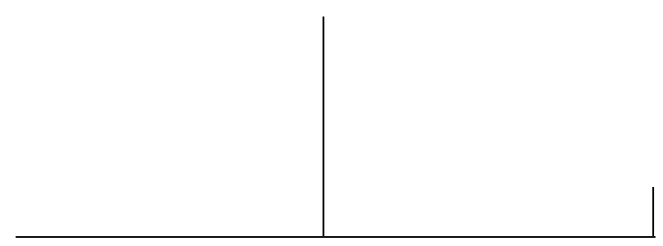

Rev. Latinoam. Psicopat. Fund., São Paulo, 16(2), 339-341, jun. 2013

Clínica do Lebenswelt: psicoterapia e psicopatologia fenomenológica Arthur Tatossian e Virgínia Moreira São Paulo: Escuta, 2012, 304 págs.

\title{
Clínica do Lebenswelt: psicoterapia e psicopatologia fenomenológica
}

Ana Maria Lopez Calvo de Feijoo

Virgínia Moreira em Clínica do Lebenswelt: psicoterapia e psicopatologia fenomenológica, sabiamente, disponibilizou-se a homenagear, postumamente, Arthur Tatossian. A primeira parte do livro é toda dedicada aos escritos de Tatossian, alguns inéditos, os quais ele apresenta com clareza, simplicidade, sem perder o rigor e a profundidade de seus temas. Na segunda parte do livro, Virgínia Moreira e seus colaboradores retomam e enraízam, ainda mais, as discussões que Tatossian trouxe, com tamanha mestria, na primeira parte do livro.

Os temas apresentados por Tatossian e Moreira podem ser resumidos em quatro grandes eixos: o tempo humano por meio do qual elaboram uma análise fenomenológica da depressão e da esquizofrenia; o inconsciente e o corpo em uma fenomenologia existencial; as dualidades da teoria e prática, do sintoma e do fenômeno e, por fim, a clínica. 
No primeiro eixo, o tempo humano é discutido em dois momentos fundamentais na fenomenologia: descritivo e constitutivo. A constituição diz respeito às alterações da subjetividade. E, assim, ao apresentar a fenomenologia da depressão e da esquizofrenia, considerando o tempo imanente à consciência e a consciência imanente do tempo, é que Tatossian e Moreira abordam com maestria a psicopatologia fenomenológica. Para tanto, eles trazem, de modo crítico, as contribuições de Jaspers, Binswanger e Boss na elaboração dessa modalidade clínica, dialogam com renomados estudiosos do tema tais como Jaspers, Minkowski, Straus, Von Gebsattel, Binswanger, Zutt, Schult, Telenbach e apresentam as fabulosas e inovadoras contribuições de Tatossian.

No segundo eixo, encontramos as considerações acerca da noção de inconsciente sob dois domínios: consciência e eu concreto humano. E também encontramos considerações sobre a fenomenologia do corpo, em que Tatossian diferencia o corpo vivido (Leib) e o corpo que tenho (Korper), concluindo que é do modo como se estabelece as relações com o corpo que surge uma série de fenômenos psicopatológicos: a histeria, algumas fobias, psicoses esquizofrênicas e delirantes, a melancolia e a mania.

$\mathrm{O}$ terceiro eixo diz respeito à postura fenomenológica diante das dicotomias teoria e prática; sintoma e fenômeno em psiquiatria. Tatossian nos remete a crítica de Husserl às teorias, apresentando a fenomenologia como busca dos pressupostos na experiência pré-objetiva, que Husserl denominou "mundo da vida", daí a valorização da unidade práxis e teoria.

Cabe agora responder as questões proposta no interior dos textos que compõem o livro, para assim esclarecer o quarto eixo de discussões: a fenomenologia pode ser uma epistemologia para a psiquiatria? Tatossian nos responde a essa questão por meio da hermenêutica e da fenomenologia, concluindo que a fenomenologia é a epistemologia da psiquiatria. E, o que é a clínica? Para responder a questão, ele se refere ao psiquiatra como sendo o último dos clínicos e aponta para dois modelos próprios a essa atividade: inferencial e perceptivo. Moreira responde a essa questão após revisitar as concepções filosóficas de Husserl, Heidegger, Merleau-Ponty, Tatossian e Telenbach para, então, reposicionar a clínica psicológica nos termos de uma indissociabilidade homem e mundo.

Chegamos ao final desta recensão e cabe sublinhar que a obra Clínica do Lebenswelt apresenta, sem dúvida nenhuma, uma valiosa contribuição para a psicoterapia e psicopatologia fenomenológica. Com a indiscutível pertinência do diálogo travado com a filosofia, sobretudo de Merleau-Ponty, os autores Arthur Tatossian e Virgínia Moreira primaram na precisão terminológica e conceitual com que desenvolveram suas ideias, sem, no entanto, debitar de clareza as suas exposições. Destacamos a extraordinária conjugação das teorias com as práticas de 
pesquisa e da clínica, sem estabelecer a prioridade de uma com relação à outra. Clínica do Lebenswelt: psicoterapia e psicopatologia fenomenológica, editado na "Coleção Phatos" pela Editora Escuta constitui-se como uma obra de inestimável e insubstituível interesse para psicólogos, psiquiatras e estudiosos desses temas.

\section{Ana Maria Lopez Calvo de Feijoo}

Doutora em Psicologia; Professor-adjunto da graduação e do Programa de Pós-Graduação da Universidade do Estado do Rio de Janeiro - UERJ (Rio de Janeiro, RJ, Br).

Universidade do Estado do Rio de Janeiro

Departamento de Psicologia Clínica - Instituto de Psicologia

Rua São Francisco Xavier, 524 - Maracanã

20.550-013 Rio de Janeiro, RJ, Br.

e-mail: ana.maria.feijoo@gmail.com.br 